\title{
Femoral Nerve Block and Intravenous Fentanyl for Positioning During Spinal Anesthesia in Surgery of Femur Fractures: Hemodynamic Changes
}

\author{
Vijay Siddhartha B S ${ }^{1}$, Ranjini BN ${ }^{2}$ \\ ${ }^{1}$ Assistant Professor, Department of Anaesthesia, East point College of Medical sciences and research centre, Bangalore, Karnataka, ${ }^{2}$ Senior Resident, \\ Department of Anaesthesia, Subbaiah Institute of Medical sciences, Shivamogga, Karnataka.
}

\section{Abstract}

Background: Fentanyl is a synthetic opioid and a phenylpiperidine derivative. It is structurally related to Pethidine, and is $75-125$ times as potent as Morphine. It is a potent lipophilic opioid. It is a $\mu$ receptor agonist with a short onset time and moderate Duration of action. Fentanyl citrate is N-(1-phenethyl-4-piperidinyl) propionanilidedi hydrogen citrate. Subjects and Methods: A pre-anesthetic evaluation comprising of history of previous medical and surgical illnesses, previous anesthesia exposures, drug allergies and upper respiratory tract infection; clinical examination and baseline investigation of blood hemoglobin, radiograph of the chest and airway examination was done.. Results: Heart rate, systolic and diastolic BP after 20 minute within and between groups. T test was applied to find any statistical difference between the groups. The statistical test showed that there was a significant difference in heart rate, systolic and diastolic blood pressure between the two groups with $\mathrm{p}$ value less than 0.05 . Conclusion: It is found that heart rate, systolic and diastolic BP start decreasing with femoral nerve block after $10^{\text {th }}$ minute. No difference in hemodynamic changes found in fentanyl group.

Keywords: Fentanyl, hemodynamic changes, Femur Fractures.

Corresponding Author: Dr. Ranjini BN, Senior Resident, Department of Anaesthesia, Subbaiah Institute of Medical sciences, Shivamogga, Karnataka.

Received: December 2019

Accepted: December 2019

\section{Introduction}

"The femoral nerve block provides analgesia to the anterior thigh, including the flexor muscles of the hip and extensor muscles of the knee. Historically this block was also known as the "3-in-1 block," suggesting that the femoral, lateral femoral cutaneous, and obturator nerves could be blocked from a single perivascular injection at the femoral Crease. Studies have since demonstrated that the femoral and lateral femoral cutaneous nerves can be reliably blocked by a single injection, but the obturator nerve is often missed. Therefore, a posterior lumbar plexus block should be used when all three nerves need to be anesthetized (although this point remains controversial). ${ }^{[1]}$

The femoral nerve block is an ideal block for surgeries of the hip, knee, or anterior thigh and is often combined with a sciatic nerve block for near complete lower extremity analgesia. Complete analgesia of the leg can be achieved without lumbar plexus block by combining a femoral nerve block with parasacral sciatic nerve block (which blocks the obturator over $90 \%$ of the time), or by adding an individual obturator nerve block to the femoral nerve block. ${ }^{[2]}$

The femoral nerve, formed by the dorsal divisions of the anterior rami of L2-L4, is the largest terminal branch of the lumbar plexus. It travels through the psoas muscle,leaving the psoas at its lateral border. The nerve then descends caudally into the thigh via the groove formed by the psoas and iliacus muscles, entering the thigh beneath the inguinal ligament. After emerging from the ligament, the femoral nerve divides into an anterior and posterior branch. At this level it is located lateral and posterior to the femoral artery. The anterior branch provides motor Innervation to the Sartorius and pectineus muscles and sensory innervation to the skin of the anterior and medial thigh. The posterior branch provides motor innervation to the quadriceps muscle (rectus-femoris, vastus-intermedius, vastus-lateralis, and vastusmedialis) and sensory innervation to the medial aspect of the lower leg via the saphenous nerve. ${ }^{[3]}$

The anatomic location of the femoral nerve makes this block one of the easiest to master because the landmarks are usually simply identified (except in cases of morbid obesity), the patient remains supine and the depth of the nerve is relatively superficial.

Fentanyl is a synthetic opioid and a phenylpiperidine derivative. It is structurally related to Pethidine, and is 75125 times as potent as Morphine. It is a potent lipophilic opioid. It is a $\mu$ receptor agonist with a short onset time and moderate Duration of action. Fentanyl citrate is N-(1phenethyl-4-piperidinyl) propionanilidedi hydrogen citrate. ${ }^{[4]}$ It is a white crystalline powder which is soluble in water and methyl alcohol. Molecular weight is 528.59 . Its pKa is 8.43 and at physiological $\mathrm{pH}$ of 7.4 , only $8.5 \%$ is unionized. 
Therapeutic index 4 times that of Morphine.

The predominant and usual effect on heart rate is to produce bradycardia resulting from stimulation of central vagal nucleus and also has direct effect on cardiac pacemaker cells. Blockade of sympathetic actions may also contribute to Opioid induced bradycardia. Fentanyl has a dose dependent positive inotropic effect. It Slows atrio ventricular node conduction and prolongs RR interval, the AV node refractory period and PURKINGE fiber action potential duration. Unlike morphine and mepiridine, fentanyl does not produce increase in plasma histamine and hypotension is less frequent with this opioid. ${ }^{[5]}$

Bupivacaine depresses rapid phases of depolarization $\left(\mathrm{V}_{\max }\right)$ in Purkinje fibres and ventricular musculature to a greater extent than Lignocaine. It also decreases the rate of recovery from a dependent block than that of Lignocaine. This leads to incomplete restoration of $\mathrm{V}_{\max }$ between action potential at high rates, in contrast complete recovery by Lignocaine. This explains why Lignocaine has antiarrhythmic property while Bupivacaine has arrhythmogenic potential. High level of Bupivacaine prolongs conduction time through various parts of heart and extremely high concentration will depress spontaneous pacemaker activity, resulting in bradycardia and arrest. Cardiac resuscitation is more difficult following Bupivacaine induced cardiovascular collapseand hypoxia along with acidosis which markedly potentiates cardiac toxicity. Bretyllium but not Lignocaine could raise the ventricular tachycardia threshold that was lowered by Bupivacaine. ${ }^{[6]}$

\section{Subjects and Methods}

\section{Group A}

In this group $(n=30)$ of patients IV fentanyl given intravenously wasadministered 30 minutes before planned neuroaxial blockade

\section{Group B}

In this group $(n=30)$ of patient peripheral nerve stimulator guided femoralnerve block was administered 30 minutes before planned neuroaxial blockade.

\section{Inclusion Criteria}

- All patients undergoing elective surgeries for proximal femur fractures.

- $\quad$ Age $>18$ years and $<65$ years

\section{Exclusion Criteria}

- $\quad$ Patients with poor GCS

- $\quad$ Age $<18$ years and $>65$ years

- Patients with liver and renal diseases

- Patients with known local anesthetic allergy

- Patient with bleeding tendencies and coagulopathy.

A pre-anesthetic evaluation comprising of history of previous medical and surgical illnesses, previous anesthesia exposures, drug allergies and upper respiratory tract infection; clinical examination and baseline investigation of blood hemoglobin, radiograph of the chest and airway examination was done.
- Informed written consent was taken from the patient.

- Patient was kept nil by mouth for 10 hours prior to surgery.

- Preoperative vitals parameters in the form of baseline pulse and blood pressure were recorded.

Results

Table 1: Comparison of Heart Rate, Systolic and Diastolic
Blood Pressures between the Two Groups
\begin{tabular}{|l|l|l|l|l|l|l|}
\hline \multirow{4}{*}{ Pre HR } & & N & Mean & $\begin{array}{l}\text { Std } \\
\text { Deviation }\end{array}$ & $\begin{array}{l}\text { t } \\
\text { value }\end{array}$ & $\begin{array}{l}\text { p } \\
\text { value }\end{array}$ \\
\cline { 2 - 7 } & Block & 30 & 89.03 & 8.12 & 0.4362 & 0.6643 \\
\cline { 2 - 7 } & Fentanyl & 30 & 89.93 & 7.86 & & \\
\cline { 2 - 7 } & Total & 60 & 89.48 & 7.94 & & \\
\hline $\begin{array}{l}\text { Pre } \\
\text { Interv } \\
\text { SBP }\end{array}$ & $\begin{array}{l}\text { Femoral } \\
\text { Block }\end{array}$ & 30 & 133.43 & 13.18 & 0.0978 & 0.9224 \\
\cline { 2 - 7 } & Fentanyl & 30 & 133.10 & 12.96 & & \\
\cline { 2 - 7 } & Total & 60 & 133.27 & 12.96 & & \\
\hline $\begin{array}{l}\text { Pre } \\
\text { Interv } \\
\text { DBP }\end{array}$ & $\begin{array}{l}\text { Femoral } \\
\text { Block }\end{array}$ & 30 & 79.6 & 4.15 & 0.4955 & 0.6221 \\
\cline { 2 - 7 } & Fentanyl & 30 & 79.06 & 4.29 & & \\
\cline { 2 - 7 } & Total & 60 & 79.33 & 4.19 & & \\
\hline
\end{tabular}

The table below shows that pre-interventional VAS score at rest and movement in each group is same.

\section{Table 2: Comparison of Heart Rate, Systolic and Diastolic}

\begin{tabular}{|c|c|c|c|c|c|c|}
\hline & & $\mathbf{N}$ & Mean & $\begin{array}{l}\text { Std } \\
\text { Deviation }\end{array}$ & $\begin{array}{l}\mathbf{t} \\
\text { value }\end{array}$ & p value \\
\hline & Femoral & 30 & 88.80 & 7.35 & 0.4009 & 0.6899 \\
\hline \multirow{3}{*}{$\begin{array}{l}\text { HR At } \\
5 \\
\text { Min }\end{array}$} & Block & & & & & \\
\hline & Fentanyl & 30 & 89.53 & 6.74 & & \\
\hline & Total & 60 & 89.16 & 6.99 & & \\
\hline \multirow{4}{*}{$\begin{array}{l}\text { SBP } \\
\text { At } 5 \\
\text { Min }\end{array}$} & Femoral & 30 & 133.23 & 13.33 & 0.0605 & 0.9520 \\
\hline & Block & & & & & \\
\hline & Fentanyl & 30 & 133.43 & 12.26 & & \\
\hline & Total & 60 & 133.33 & 12.70 & & \\
\hline \multirow{4}{*}{$\begin{array}{l}\text { DBP } \\
\text { At } 5 \\
\text { Min }\end{array}$} & Femoral & 30 & 79.60 & 4.14 & 0.1975 & 0.8441 \\
\hline & Block & & & & & \\
\hline & Fentanyl & 30 & 79.80 & 3.69 & & \\
\hline & Total & 60 & 79.70 & 3.89 & & \\
\hline
\end{tabular}

\section{T Test}

This table shows comparison of heart rate, systolic and diastolic BP within and between groups. T test was applied to check for any statistical significance. $p$ value was not less than 0.05 and hence no statistical significance noted $(\mathrm{p}=0.68, \mathrm{p}=0.95, \mathrm{p}=0.84)$. This shows that there is no change in heart rate, systolic and diastolic BP after 5 minute in each group.

The table below shows the VAS score at rest and movement in each group is same after 5 minutes.

\section{Student T Test}

The above table shows heart rate, systolic and diastolic BP after 10 minute within and between groups. T test was applied to find any statistical difference between the groups. The statistical test showed that there was a significant difference in heart rate between the two groups with $\mathrm{p}$ value of 0.02 which is less than 0.05 . $\mathrm{P}$ value of systolic and diastolic blood pressure did not show any statistical difference $(\mathrm{p}=0.2123, \mathrm{p}=0.2084)$. This shows that there is 
significant change in heart rate only after 10 minutes.

The table also indicates that heart rate, systolic blood pressure and diastolic blood pressure start decreasing after 10 minutes in femoral nerve block in comparison with IV fentanyl group which was noted clinically even though significant statistical difference was not there in blood pressures.

Table 3: Comparison of Heart Rate, Systolic and Diastolic Blood Pressures of Patients Belonging To Both the Groups at 10 Minutes

\begin{tabular}{|c|c|c|c|c|c|c|}
\hline & & $\mathbf{N}$ & Mean & $\begin{array}{l}\text { Std } \\
\text { Deviation }\end{array}$ & $\begin{array}{l}\mathrm{t} \\
\text { value }\end{array}$ & $\begin{array}{l}\mathbf{p} \\
\text { value }\end{array}$ \\
\hline \multirow{4}{*}{$\begin{array}{l}\text { HR At } \\
10 \mathrm{~m}\end{array}$} & Femoral & 30 & 85.76 & 6.48 & 2.2710 & $0.0269 *$ \\
\hline & Block & & & & & \\
\hline & Fentanyl & 30 & 89.26 & 5.41 & & \\
\hline & Total & 60 & 87.51 & 6.18 & & \\
\hline \multirow{4}{*}{$\begin{array}{l}\text { SBP at } \\
10 \mathrm{~m}\end{array}$} & Femoral & 30 & 130.73 & 10.82 & 1.2612 & 0.2123 \\
\hline & Block & & & & & \\
\hline & Fentanyl & 30 & 134.26 & 10.86 & & \\
\hline & Total & 60 & 132.50 & 10.90 & & \\
\hline \multirow{4}{*}{$\begin{array}{l}\text { DBP } \\
\text { at } \\
10 \mathrm{~m}\end{array}$} & Femoral & 30 & 79.26 & 4.11 & 1.2723 & 0.2084 \\
\hline & Block & & & & & \\
\hline & Fentanyl & 30 & 80.46 & 3.13 & & \\
\hline & Total & 60 & 79.86 & 3.68 & & \\
\hline
\end{tabular}

The heart rate, systolic and diastolic BP after 15 minute within and between groups. T test was applied to find any statistical difference between the groups. The statistical test showed that there was a significant difference in heart rate, systolic and diastolic blood pressure between the two groups with $p$ value less than 0.05 . Thus the heart rate, systolic and diastolic blood pressures were significantly lower in femoral nerve block group when compared to fentanyl group.

The heart rate, systolic and diastolic BP after 20 minute within and between groups. $\mathrm{T}$ test was applied to find any statistical difference between the groups. The statistical test showed that there was a significant difference in heart rate, systolic and diastolic blood pressure between the two groups with $\mathrm{p}$ value less than 0.05 . Thus the heart rate, systolic and diastolic blood pressures were significantly lower in femoral nerve block group when compared to fentanyl group.

Table 4: Comparison of Heart Rate, Systolic and Diastolic Blood Pressures of Patients Belonging To Both the Groups at 25 Minutes

\begin{tabular}{|l|l|l|l|l|l|l|}
\hline \multirow{2}{*}{} & & N & Mean & $\begin{array}{l}\text { Std } \\
\text { Deviation }\end{array}$ & $\begin{array}{l}\text { t } \\
\text { value }\end{array}$ & p value \\
\hline \multirow{2}{*}{$\begin{array}{l}\text { HR at } \\
\text { min }\end{array}$} & $\begin{array}{l}\text { Femoral } \\
\text { Block }\end{array}$ & 30 & 77.1 & 5.32 & 7.280 & $<0.0001^{*}$ \\
\cline { 2 - 7 } & Fentanyl & 30 & 85.06 & 2.75 & & \\
\cline { 2 - 7 } & Total & 60 & 81.08 & 5.81 & & \\
\hline $\begin{array}{l}\text { SBP } \\
\text { at 25 } \\
\text { min }\end{array}$ & $\begin{array}{l}\text { Femoral } \\
\text { Block }\end{array}$ & 30 & 126.33 & 7.26 & 4.347 & $<0.0001^{*}$ \\
\cline { 2 - 7 } & Fentanyl & 30 & 134.53 & 7.35 & & \\
\cline { 2 - 7 } & Total & 60 & 130.43 & 8.34 & & \\
\hline \multirow{2}{*}{$\begin{array}{l}\text { DBP } \\
25 \\
\text { min }\end{array}$} & $\begin{array}{l}\text { Femoral } \\
\text { Block }\end{array}$ & 30 & 78.6 & 3.72 & 3.041 & $0.0035^{*}$ \\
\cline { 2 - 7 } & Fentanyl & 30 & 80.93 & 1.94 & & \\
\cline { 2 - 7 } & Total & 60 & 79.76 & 3.16 & & \\
\hline
\end{tabular}

The heart rate, systolic and diastolic BP after 20 minute within and between groups. $\mathrm{T}$ test was applied to find any statistical difference between the groups. The statistical test showed that there was a significant difference in heart rate, systolic and diastolic blood pressure between the two groups with $\mathrm{p}$ value less than 0.05 .

Table 5: Comparison of Heart Rate, Systolic and Diastolic Blood Pressures of Patients Belonging To Both the Groups at 30 Minutes

\begin{tabular}{|c|c|c|c|c|c|c|}
\hline & & $\mathbf{N}$ & Mean & $\begin{array}{l}\text { Std } \\
\text { Deviation }\end{array}$ & t value & p value \\
\hline \multirow{3}{*}{$\begin{array}{l}\text { HR at } \\
30^{\text {th }} \\
\text { Min }\end{array}$} & $\begin{array}{l}\text { Femoral } \\
\text { Block }\end{array}$ & 30 & 75.63 & 4.91 & 11.5233 & $<0.0001^{*}$ \\
\hline & Fentanyl & 30 & 86.8 & 2.02 & & \\
\hline & Total & 60 & 81.21 & 6.75 & & \\
\hline \multirow{3}{*}{$\begin{array}{l}\text { SBP } \\
\text { at } \\
30^{\text {th }} \\
\text { Min }\end{array}$} & $\begin{array}{l}\text { Femoral } \\
\text { Block }\end{array}$ & 30 & 126.66 & 6.97 & 4.2748 & $<0.0001 *$ \\
\hline & Fentanyl & 30 & 133.06 & 4.32 & & \\
\hline & Total & 60 & 129.86 & 6.59 & & \\
\hline \multirow{3}{*}{$\begin{array}{l}\text { DBP } \\
\text { at } \\
30^{\text {th }} \\
\text { min }\end{array}$} & $\begin{array}{l}\text { Femoral } \\
\text { Block }\end{array}$ & 30 & 78.4 & 3.46 & 4.0681 & $<0.0001^{*}$ \\
\hline & Fentanyl & 30 & 81.2 & 1.61 & & \\
\hline & Total & 60 & 79.8 & 3.04 & & \\
\hline
\end{tabular}

The above table shows heart rate, systolic and diastolic BP after 20 minute within and between groups. T test was applied to find any statistical difference between the groups. The statistical test showed that there was a significant difference in heart rate, systolic and diastolic blood pressure between the two groups with $\mathrm{p}$ value less than 0.05 .

\section{Discussion}

In our study age and sex are not confounding factors and hence study is comparable on the basis of demographic data. Femoral nerve block provide excellent analgesia for positioning than IV fentanyl group.

Hemodynamic parameters like heart rate, systolic and diastolic BP are also noted in which significant decrease is found in femoral nerve block. Hence femoral nerve block shows more hemodynamic stability than IV fentanyl.

Intertrochanteric and femoral neck fractures account for $90 \%$ of the proximal femoral fractures occurring in elderly patients which require surgical intervention. Proximal femoral fractures are very common in patients older than 50 years which are mostly pathological. In younger patients, proximal femoral fractures are usually the result of highenergy physical trauma (eg, high speed motor vehicle accidents) and usually occur in the absence of disease. Displaced fractures are very painful and don't allow the patient to move. It is very difficult to give proper positioning during administration of neuroaxial blockade in such patients because of pain. Fracture of femur is a particularly painful bone injury because the periosteum has the lowest pain threshold of the deep somatic structure

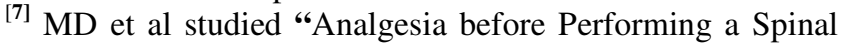
Block in the Sitting Position in Patients with Femoral Shaft Fracture: A Comparison between Femoral Nerve Block and Intravenous Fentanyl". They concluded that femoral nerve block is better than IV fentanyl for giving position for spinal block in femur surgeries.Mutty CE, Jensen $E \mathrm{~J}^{[8]}$ et all studied efficacy of femoral nerve block for diaphyseal and distal femoral fractures in emergency department in pain management. They found that the acute pain of a diaphyseal or distal femoral fracture can be significantly decreased 
through the use of a femoral nerve block, which can be administered safely in the hospital emergency department. Arissara Iamaroon" ${ }^{[9]}$ et al studied "Femoral nerve block versus fentanyl: Analgesia for positioning patients with fractured femur" in 64 patients. They were unable to demonstrate benefit of femoral nerve block over IV fentanyl in positioning for spinal block. They found femoral nerve block provide good post-operative analgesia and complication rate is less in block than IV fentanyl. ${ }^{[10]}$

This is the prospective, randomized study in which the feasibility and analgesic effect of femoral nerve block and IV fentanyl administration were compared. Here we randomly divided the patients in two groups; Group A; are received peripheral nerve stimulator guided femoral nerve block, and group B received IV fentanyl. Pain score in the form of visual analogue scale is noted. Similarly heart rate, systolic and diastolic BP were noted after every 5 minute up to 30minute after intervention.

In our study demographic data (age, sex) was comparable in all groups.

The age of the cases were ranging from 18 to 65 yrs. with the mean for group A (femoral nerve block) was $46.16 \pm 4.87$ and mean for group B (fentanyl) was 45.20 \pm 4.43 ) and mean which is not statistically significant. Out of 30 participants in group A 19 were female and 11 were male; in group B 21 females and 9 males. This was also statistically not significant. Thus the demographic data of three groups were not statistically significant that means all groups were comparable and randomised properly.

Here one of the aims of study is to compare the hemodynamic changes occurring in each study group. It is found that heart rate, systolic and diastolic BP start decreasingwith femoral nerve block after $10^{\text {th }}$ minute. No difference in hemodynamic changes found in fentanyl group.

\section{Conclusion}

Femoral nerve block is more advantageous than IV Fentanyl to facilitate the sitting position for neuroaxial blockade in patients undergoing surgery for femur fractures.

They provide good analgesia and hemodynamic stability during positioning in patients with fracture femur.

\section{References}

1. Chakraborty. S, Dixit.S, Jadon A, Kedia SK, Comparative evaluation of femoral nerve block and intravenous fentanyl for positioning during spinal anesthesia in surgery of femur fracture. Indian Journal of Anesthesia, 2014; 58(6): 705-708.

2. Sia, Salvatore MD, Pelusio, Francesco MD, Barbagli, Remo MD, Rivituso, Calogero MD. Analgesia before Performing a Spinal Block in the Sitting Position in Patients with Femoral Shaft Fracture: A Comparison between Femoral Nerve Block and Intravenous Fentanyl. Anesthesia \& Analgesia2004; 99(4): 1221-1224.

3. Iamaroon A, Raksakietisak M, Halilamien P, Hongsawad J, Boonsararuxsapong. Femoral nerve block versus fentanyl: Analgesia for positioning patients with fractured femur. Local RegAnesth 2010; 25(3): 21-6.

4. Durrani HD, Butt KJ, Khosa AH, Umer A, Pervaiz M. Pain Relief during Positioning for Spinal Anesthesia in patients with Femoral Fracture: A Comparison between Femoral Nerve Block and Intravenous Nalbuphine.

5. ForouzanA, MasoumiK, YadegarN, Rahim F, FeliM and Darian AA. Comparison of Femoral Nerve Block with Intravenous Morphine Sulfate for Pain Relief of Femoral Fracture.Asian journal of scientific research 2015; 8(3): 429-35.

6. MickSerpell: Anatomy, Physiology and Pharmacology of pain. Anaesthesia and intensive care.2005; 6.1:7-10

7. Salvatore Sia, Francesco Pelusio; Analgesia before Performing a Spinal Block in the Sitting Position in Patients with Femoral Shaft Fracture: A Comparison between Femoral Nerve Block and Intravenous Fentanyl. AnesthAnalg. 2004

8. Mutty CE, Jensen EJ' Efficacy of femoral nerve block for diaphyseal and distal femoral fractures in emergency department in pain management. J Bone JointSurg Am. 2007 Dec; 89(12):2599-603.

9. ArissaraIamaroon, ManeeRaksakietisak; Femoral nerve block versus fentanyl: Analgesia for positioning patients with fractured femur. Local RegAnesth 2010;3: 21-26.

10. R Mcglone, K Sadhra; Femoral nerve block for analgesic action in femur shaft fracture in emergency department. Archives of $\begin{array}{lllr}\text { Emergency } & \text { Medicine, } & 1987, & 4,\end{array}$

Copyright: () the author(s), publisher. Academia Anesthesiologica Internationalis an Official Publication of "Society for Health Care \& Research Development". It is an open-access article distributed under the terms of the Creative Commons Attribution Non-Commercial License, which permits unrestricted non-commercial use, distribution, and reproduction in any medium, provided the original work is properly cited.

How to cite this article: Vijay Siddhartha B S, Ranjini BN. Femoral Nerve Block and Intravenous Fentanyl for Positioning During Spinal Anesthesia in Surgery of Femur Fractures: Hemodynamic Changes. Acad. Anesthesiol. Int. 2019;4(2):346-49.

DOI: dx.doi.org/10.21276/aan.2019.4.2.78

Source of Support: Nil, Conflict of Interest: None declared. 